Volume 8, No.4, July - August 2019

International Journal of Advanced Trends in Computer Science and Engineering

Available Online at http://www.warse.org/IJATCSE/static/pdf/file/ijatcse100842019.pdf

https://doi.org/10.30534/ijatcse/2019/100842019

\title{
Design and Implementation of Dual Notch Band Characteristics in UWB Antenna for Wireless Personal Communications
}

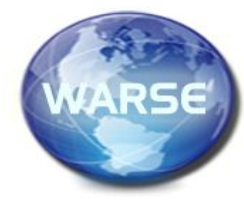

\author{
V. Subba Reddy ${ }^{1}$, M. Siva Ganga Prasad ${ }^{2}$, B T P Madhav ${ }^{3}$ \\ C R\&D, Dept of ECE, Koneru Lakshmaiah Education Foundation, Vaddeswaram, A.P, India \\ ${ }^{1}$ subbu.vasipalli@kluniversity.in
}

$20 \times 1 \mathrm{~mm}^{3}$ and with a circular ring [2], for the frequencies between 3-6 GHz a Y-Shape strip with the defected ground plane technique were effectively implemented for wireless applications [3]. A microstrip-fed antenna with the size of 16 $\square 18 \mathrm{~mm}$ was proposed, dual band operations for WLAN/Bluetooth for implementing UWB applications. In [4], monopole antennas with three arc-shaped monopole strips and dual L-shaped slots extending from the ground plane are designed respectively. Both these designs resonate in three bands suitable for Wi-MAX/WLAN applications. In [5], rhombic slot antennas with a couple of etched inverted U-shaped slots with $-10 \mathrm{~dB}$ return loss for multi-bands was developed. A swastika shape radiating patch antenna with a slotted square as the ground structure was proposed low-frequency applications. Dual-band antennas for WLAN applications are proposed.

An E- and L-Shaped radiating elements generated two resonant modes fed by microstrip line is proposed in [6], to cover two higher bands and a lower band of a WLAN system. Patch antenna with structures like rectangular, circular, rhombic, and annular rings are modeled for dual-band operations to implement IEEE $802.11 \mathrm{a} / \mathrm{b} / \mathrm{g}$ using the self-similarity property [7]. A triple-band microstrip antenna using double T-shaped slots with L-shaped feed is reported. A modified staircase shaped monopole antenna fed by CPW with L-shaped strip for UWB band is proposed. In [8], L-shaped monopole antenna with microstrip-fed for high and low-frequency bands of WLAN is reported in the size of a smartphone. In [9], Notch band characteristics for WLAN is obtained by using a tapered step with a circular patch, while MIMO structure reduces the polarization diversity issues. By using tapered steps on a ground plane with UBG structure bandwidth was observed.

The antenna proposed is a circular fractal antenna with a notch band characteristic. By including $U$ slot in the feed getting the notch band characteristics, the width and position variables are modified to get the UWB bandwidth. In [10], by altering the feed area, adding another fractal geometry to a wire square circle receiving wire a UWB antenna is proposed. Using a staircase and inverted staircase structures are proposed for UWB applications in [11]. Three resonant modes were characterized for ACS-fed monopole antenna using dual mirror L-shaped radiating structure. In an antenna comprising of the rectangular patch with dual U-shaped slots are fed by CPW mechanism, that can generate three distinct 
operating bands is proposed. Metamaterials are a class of artificial material which provides properties that are not readily available in nature. SRR and CSRR are metamaterial inspired structures, due to their unusual electromagnetic properties they are embedded in antennas for size miniaturization, multiband operation, bandwidth, and gain enhancement. SRR is used to produce desired magnetic susceptibility. The CSRR base 5G communication antenna is designed, simulated using HFSS and measured results are presented in [12]. The antenna had good isolation enhancement comparing with previous literature. The band reject filters using SRR and CSRR are designed, analyzed and carrying experimentation is presented in this article.

From the previous studies, the antennas have limited bandwidth, complex structures and only a few of them can cover multiple bands. The presented characterized antenna is a compact staircase rectangular patch with Dual notch characteristics for a compact line of site communications. The dual notch band characteristics are obtained by using SRR and CSRR on a staircase shaped rectangular patch. The antenna was designed using CST Microwave Studio suite software using FR4 substrate with 50-ohm feed and CPW ground plane.

\section{ANTENNA DESIGN}

A monopole antenna with dual-band notch was designed using Coplanar waveguide (CPW) feed. The structure is designed using the rectangular structure with staircase shaped radiating patch with SRR and CSRR for WiMAX, WLAN and Ultra-Wide Band applications. Figure 1 demonstrates the geometry of the proposed UWB antenna for dual notch applications.

The overall size of antenna $20 \times 17 \mathrm{~mm}^{2}$ is designed using FR4 substrate with $\varepsilon_{\mathrm{r}}=4.3$, the thickness $(\mathrm{H})$ is $0.8 \mathrm{~mm}$, $\tan \delta$ $=0.02$ and making the proposed antenna very compact and optimized. The CPW-fed line length $\left(\mathrm{L}_{\mathrm{f}}\right)$, width $\left(\mathrm{W}_{\mathrm{f}}\right) 5.1 \mathrm{~mm}$ and $2.6 \mathrm{~mm}$ respectively. The distance between ground plane and feedline is $0.2 \mathrm{~mm}$ was considered to match a $50-\mathrm{ohm}$ impedance. The length and width of coplanar ground planes are $4 \mathrm{~mm}$ and $7 \mathrm{~mm}$. The SRR and CSRR slots widths are 0.5 $\mathrm{mm}$ and $0.6 \mathrm{~mm}$ respectively. All the dimensions of the dual notch antenna are optimized and represented in Table 1.

Table 1: Parameters of the dual notch band antenna

\begin{tabular}{|c|c|c|}
\hline S. No & Parameter & $\begin{array}{c}\text { Dimensions } \\
\text { (in mm) }\end{array}$ \\
\hline 1 & $\mathrm{~L}$ & 20 \\
\hline 2 & $\mathrm{~W}$ & 17 \\
\hline 3 & $\mathrm{H}$ & 0.8 \\
\hline 4 & $\mathrm{~L}_{\mathrm{f}}$ & 5.1 \\
\hline 5 & $\mathrm{~W}_{\mathrm{f}}$ & 2.6 \\
\hline 6 & $\mathrm{~L}_{\mathrm{g}}$ & 4 \\
\hline 7 & $\mathrm{~W}_{\mathrm{g}}$ & 7 \\
\hline
\end{tabular}

\begin{tabular}{|c|c|c|}
\hline 8 & $\mathrm{~L}_{\mathrm{p}}$ & 11.5 \\
\hline 9 & $\mathrm{~W}_{\mathrm{p}}$ & 12 \\
\hline 10 & $\mathrm{~T}_{\mathrm{p}}$ & 0.0256 \\
\hline 11 & $\mathrm{R} 1$ & 4.7 \\
\hline 12 & $\mathrm{R} 2$ & 4.2 \\
\hline 13 & $\mathrm{R} 3$ & 3.7 \\
\hline 14 & $\mathrm{R} 4$ & 3.1 \\
\hline 15 & $\mathrm{~L} 1$ & 1 \\
\hline 16 & $\mathrm{~L} 2$ & 1 \\
\hline 17 & $\mathrm{~L} 3$ & 1 \\
\hline 18 & $\mathrm{~W} 1$ & 6 \\
\hline 19 & $\mathrm{~W} 2$ & 8 \\
\hline 20 & $\mathrm{~W} 3$ & 10 \\
\hline
\end{tabular}

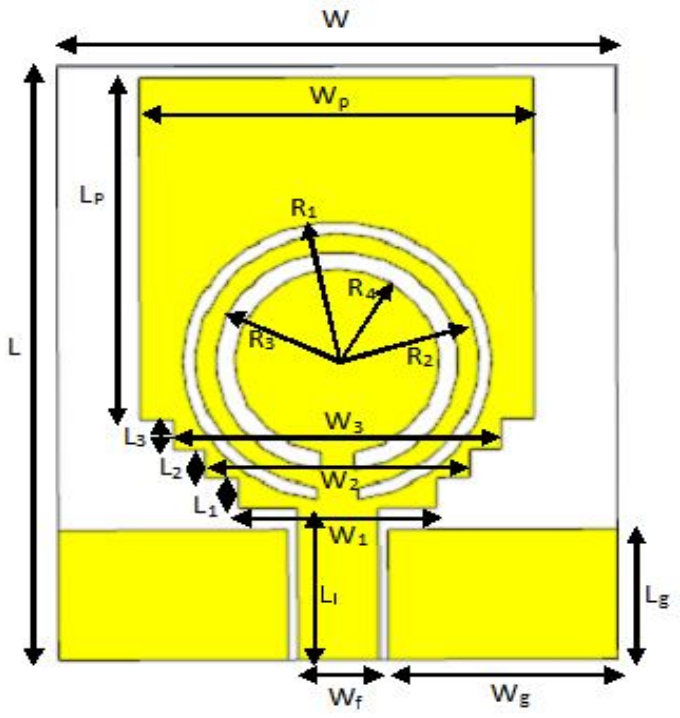

Figure 1: Geometry of the proposed dual notch band CPW antenna.

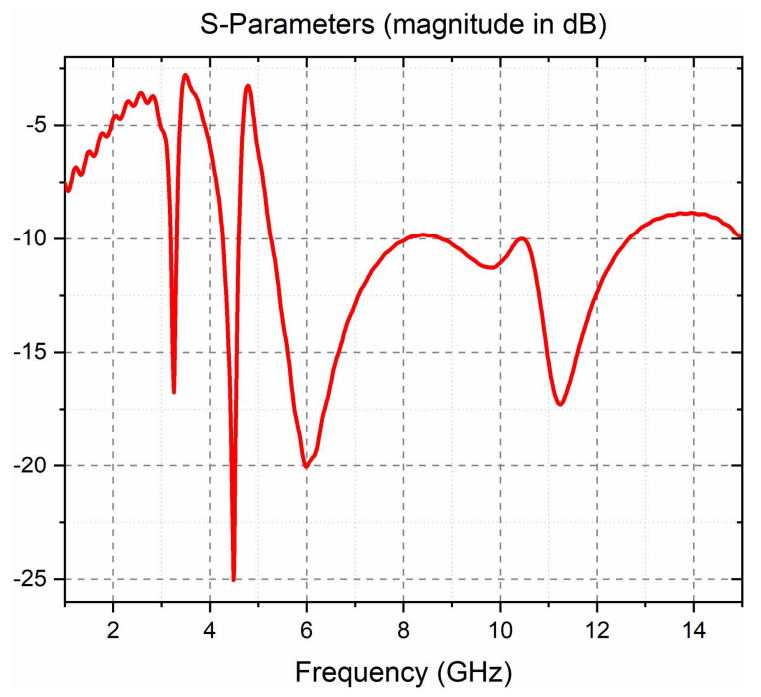

(a) 


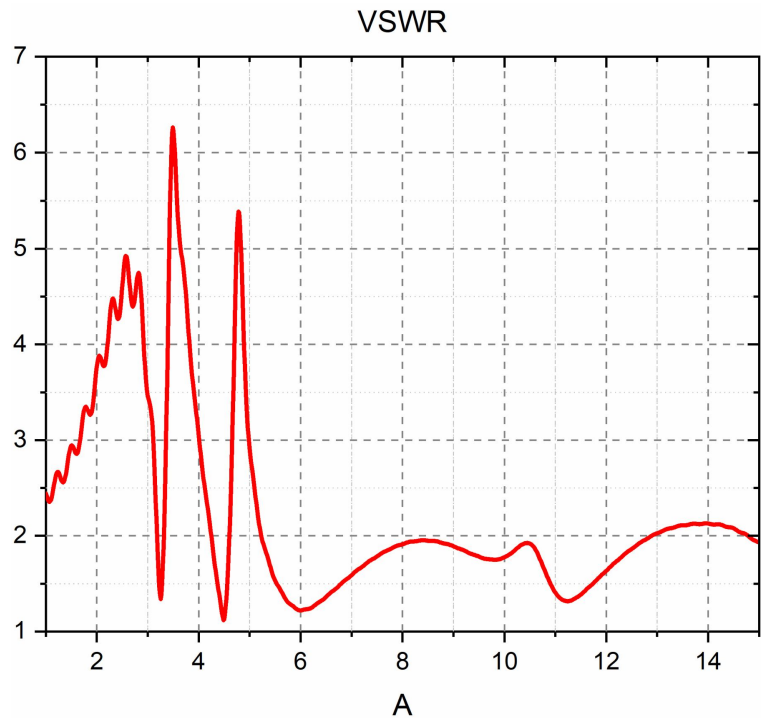

(b)

Figure 2: Simulated plots of (a) RL (b) VSWR of the dual notch band antenna

The SRR and CSRR used to get dual notch characteristics for two frequency bands. In this model, a single CSRR is implemented inside an SRR on the rectangular patch. The SRR is used to get the first stopband characteristics in the frequency range of $3.216 \mathrm{GHz}-3.99 \mathrm{GHz}$ the operating range of WiMAX. The CSRR is used to get the second stopband characteristics in the frequency range of $4.29 \mathrm{GHz}-4.78 \mathrm{GHz}$ the operating range of WLAN. The corresponding plots for Return Loss vs Frequency and VSWR vs frequency are plotted to depict the operational ranges of the two bands in figure 2 .

\section{RESULTS AND DISCUSSIONS}

This dual notch band antenna has been simulated and observed the return loss and VSWR for varying feed line widths, the height of substrate, length of patch and different radii of the SRR and CSRR. The return loss (RL) and VSWR plots in figure 3 for variable widths of feed indicate the narrow change in it, causes a small variation in the RL and VSWR. Although the plots coincided for the frequencies with a RL of $-25 \mathrm{~dB}$ at $4.5 \mathrm{GHz},-18 \mathrm{~dB}$ at $3.2 \mathrm{GHz}$. From figure 4, the optimized height of the antenna is taken as $0.8 \mathrm{~mm}$. For a patch length of $11 \mathrm{~mm}$ and $11.5 \mathrm{~mm}$, the results are almost similar with a promising return loss of $-25 \mathrm{~dB}$ at $4.5 \mathrm{GHz}$ frequency in figure 5. But even for another $0.5 \mathrm{~mm}$ rise in patch length i.e. at a length of $12 \mathrm{~mm}$, the antenna has a RL of $-45 \mathrm{~dB}$ at a frequency of $4.9 \mathrm{GHz}$.

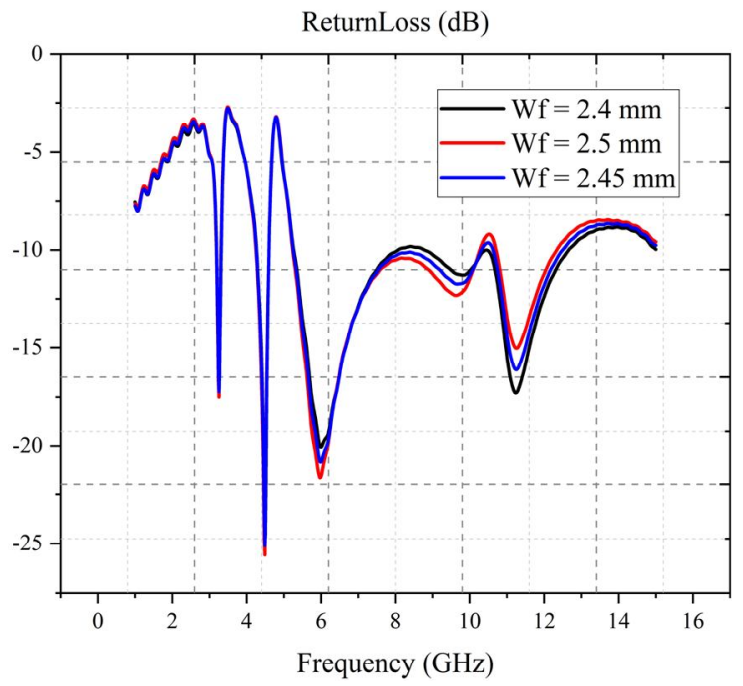

(a)

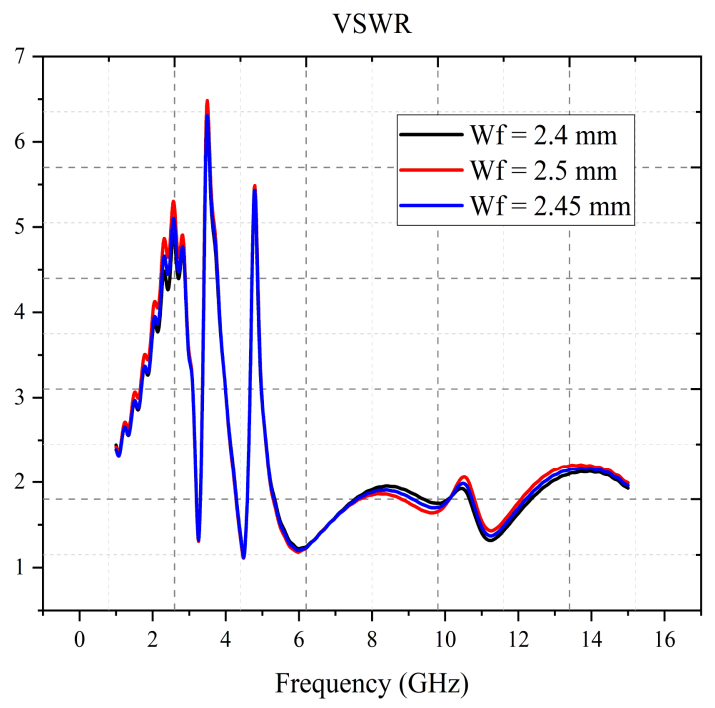

(b)

Figure 3: (a) RL (b) VSWR plot for varying $\mathrm{W}_{\mathrm{f}}$

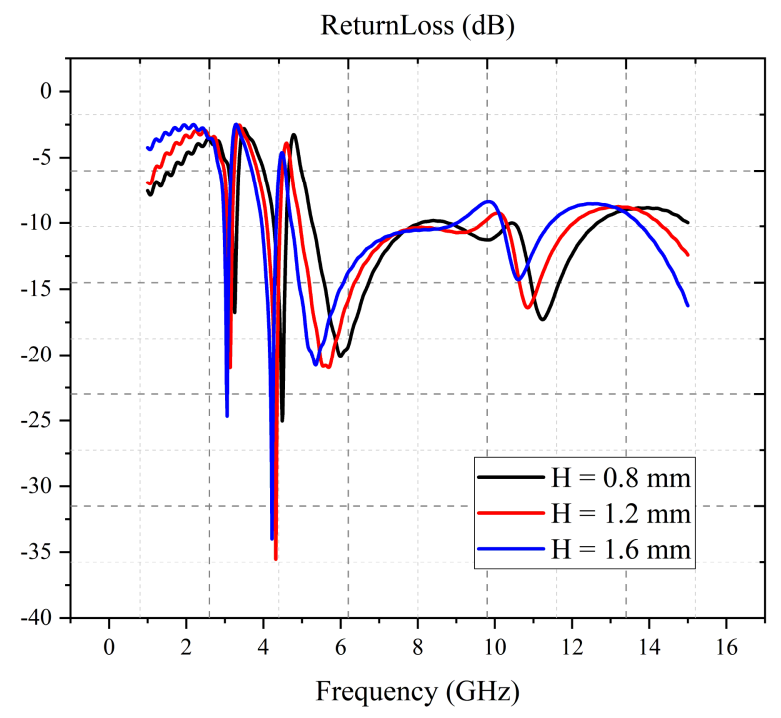

(a) 


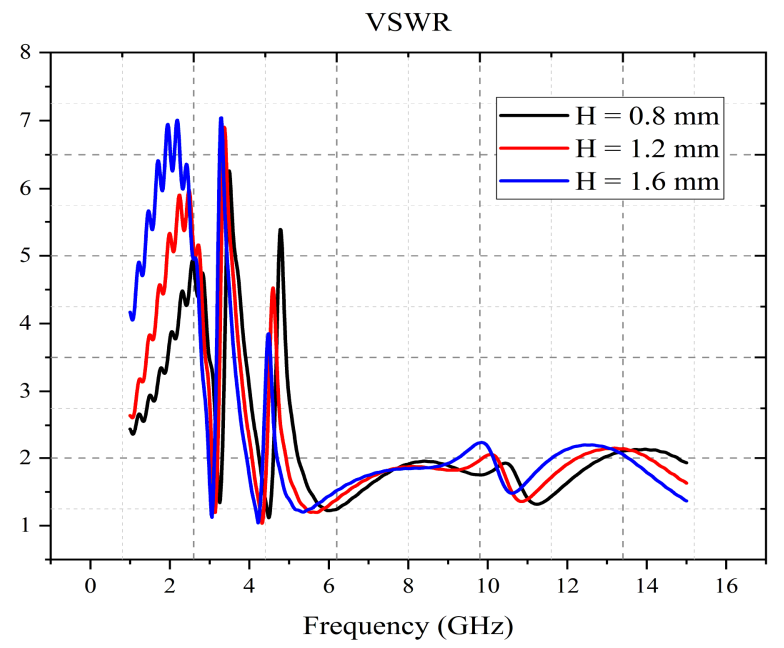

(b)

Figure 4: (a) RL (b) VSWR plot for varying $H$

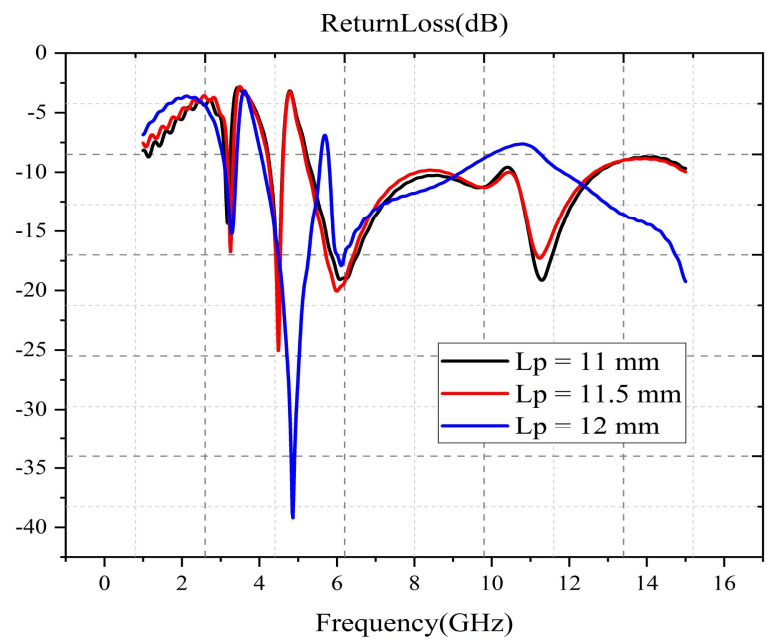

(a)

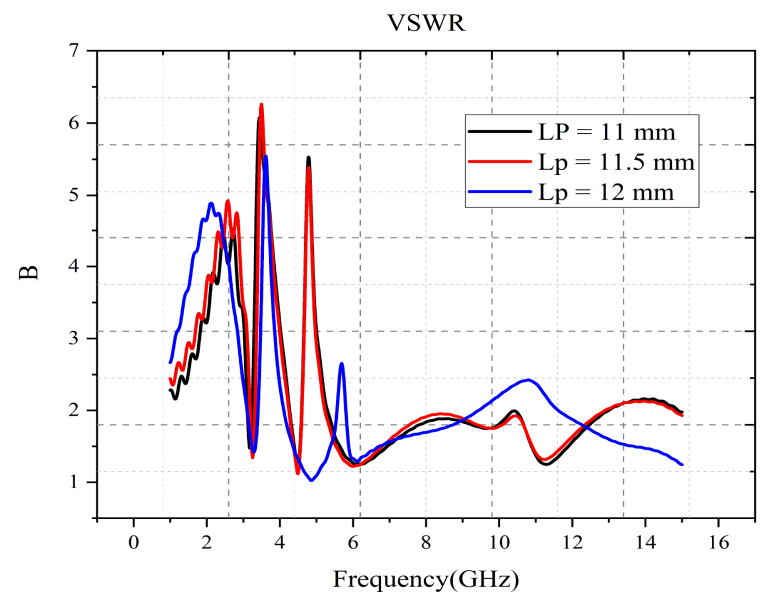

(b)

Figure 5: (a) RL (b) VSWR plot for varying $L_{p}$

From figure 6 and figure 7 shows the RL and VSWR of the change in radius of the SRR and CSRR. The change in radius also affects the RL and VSWR performance of the dual notch band antenna. The optimized radius of SRR and CSRR are R1 $=4.7 \mathrm{~mm}, \mathrm{R} 2=4.2 \mathrm{~mm}, \mathrm{R} 3=3.7 \mathrm{~mm}, \mathrm{R} 4=3.1 \mathrm{~mm}$.

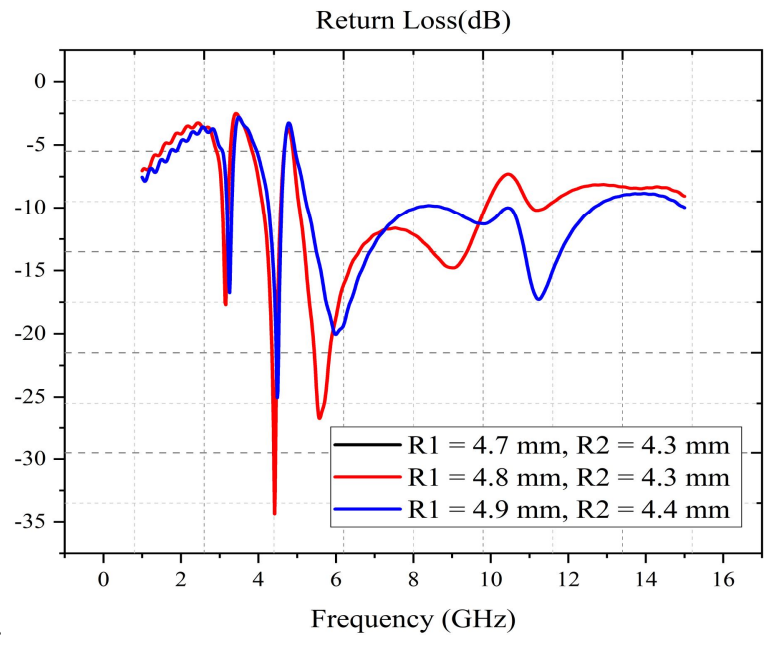

(a)

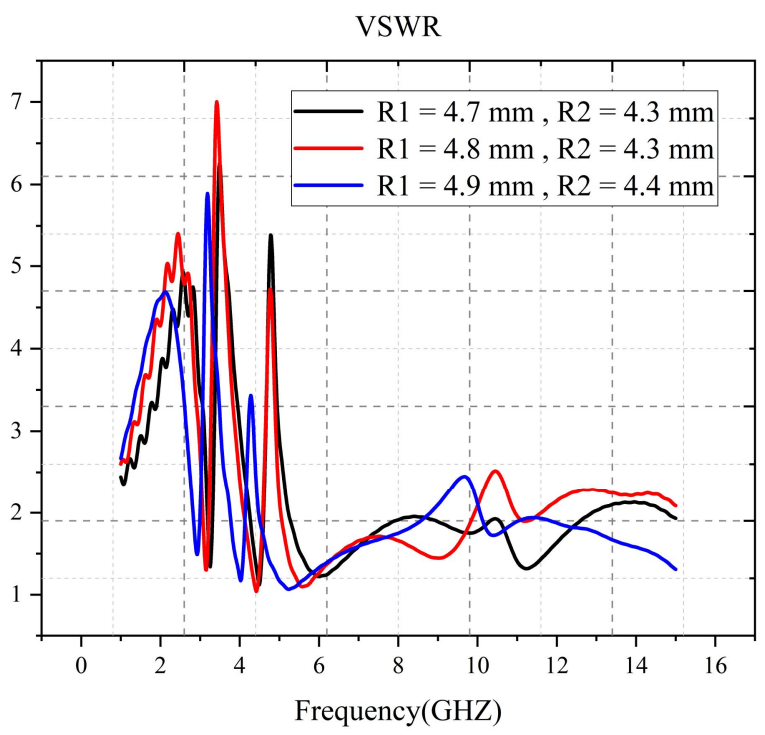

(b)

Figure 6: (a) RL (b) VSWR plot for varying R1, R2

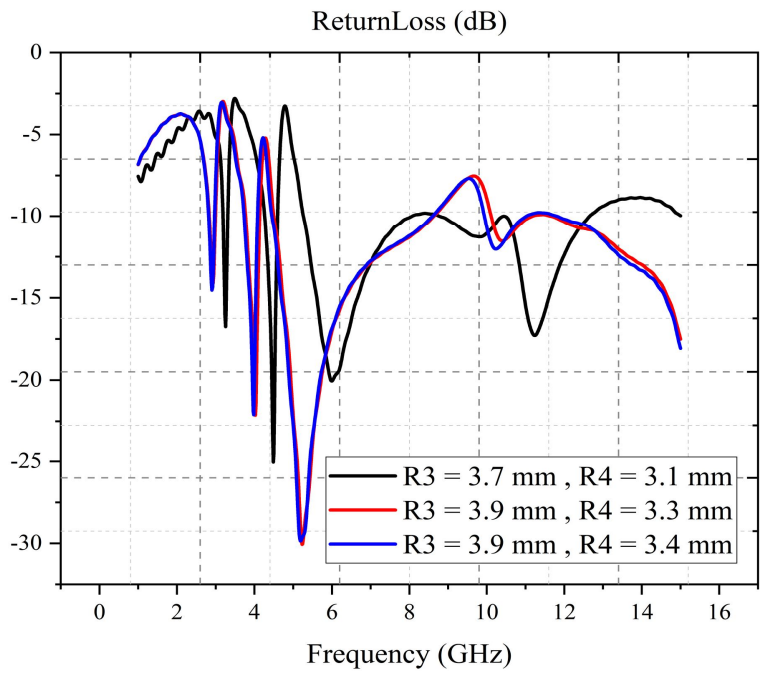

(a) 


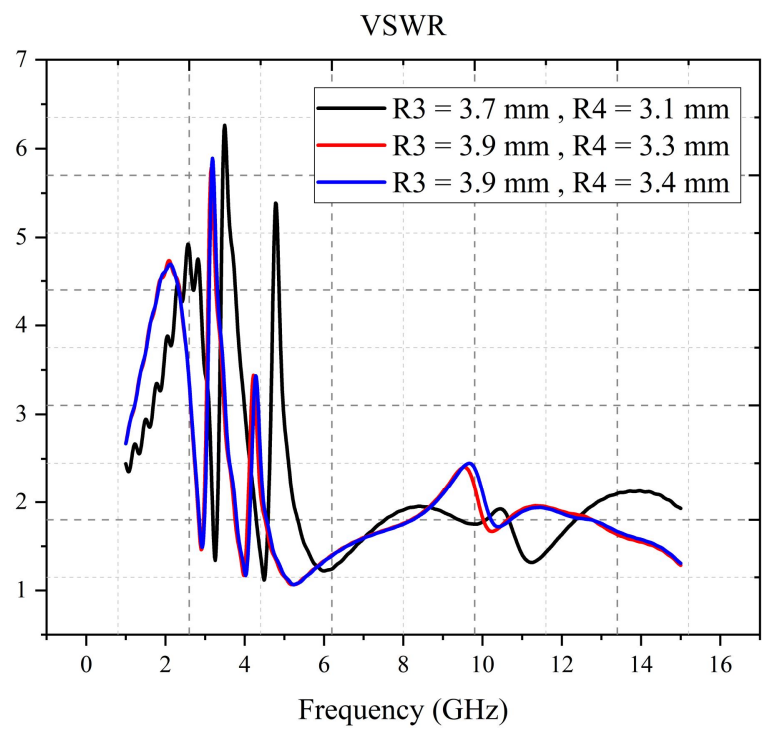

(b)

Figure 7: (a) RL (b) VSWR plot for varying R3, R4

The optimized dual notch band UWB antenna is fabricated and carried measurements using Anritsu Model number MS2037C (VNA Master). Figures 8 and 9 show the fabricated prototype and the testing setup used to measure the antenna characteristics respectively. The measured results show that $|\mathrm{S} 11| \leq-10 \mathrm{~dB}$ for the operating bands from $3.216 \mathrm{GHz}-3.99$ $\mathrm{GHz}$ and from $4.29 \mathrm{GHz}-4.78 \mathrm{GHz}$ respectively. This results the proposed UWB antenna can be used for notching the WiMAX/WLAN frequencies in UWB band. The simulated and experimental result variations are due to fabrication tolerances and SMA connector losses. Figure 10 shows the measured RL and VSWR. The measured results are almost similar performance with the simulated results.

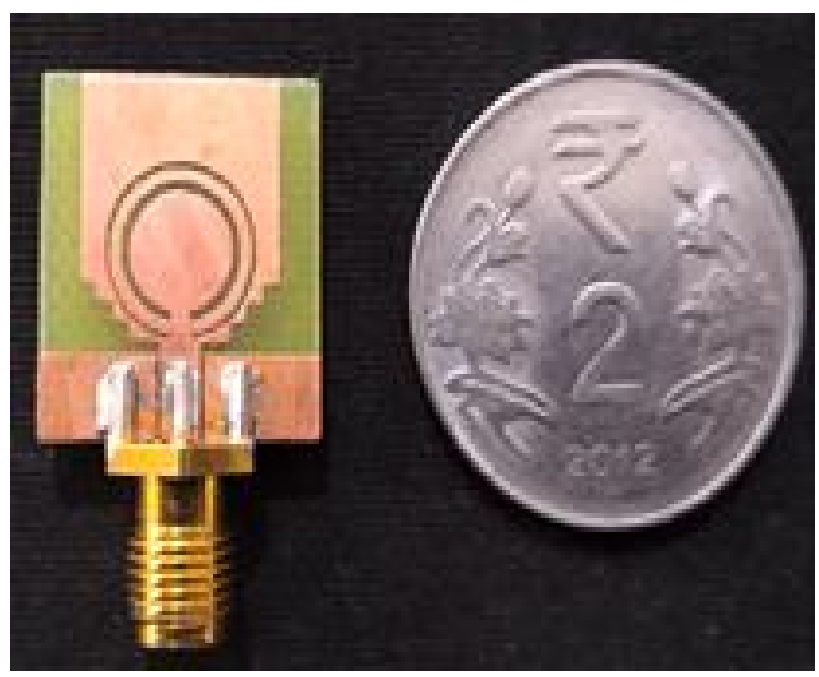

Figure 8: Prototype of the dual notch band antenna.

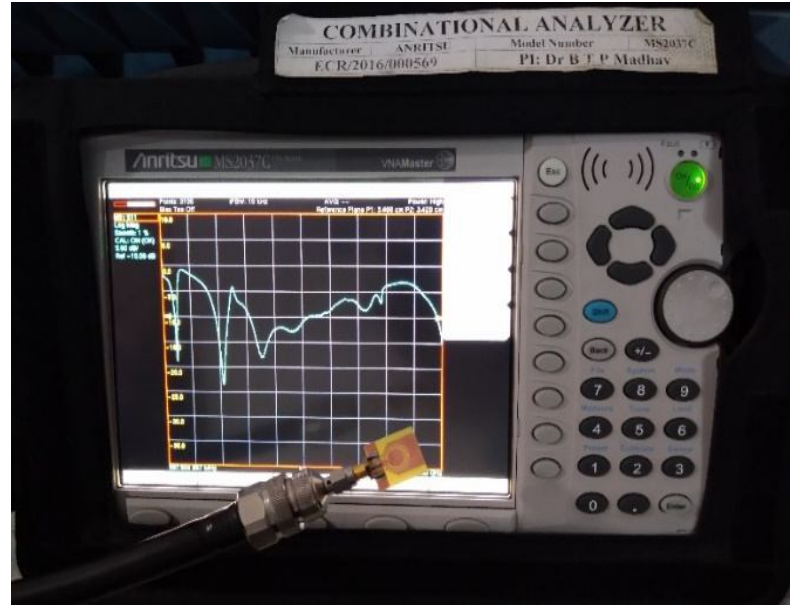

Figure 9: Testing setup for the proposed antenna

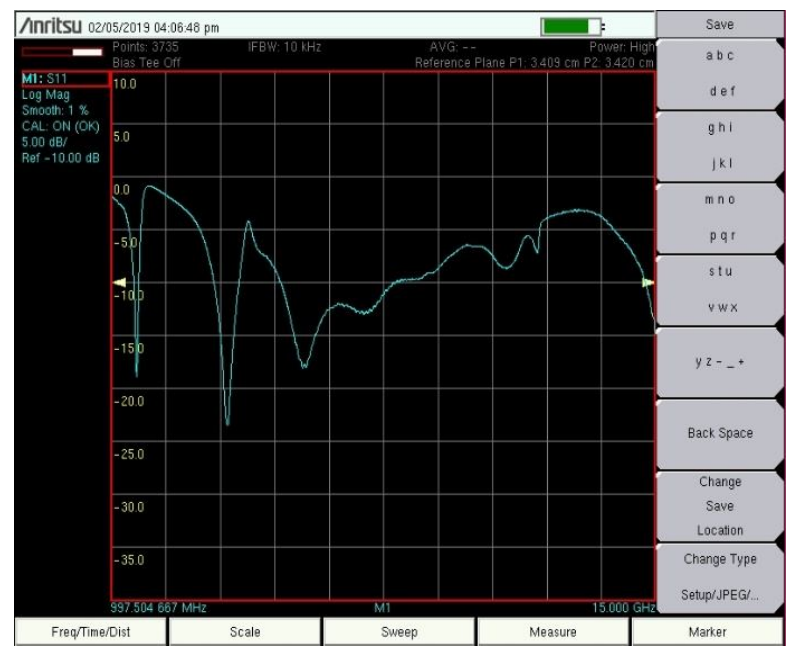

(a)

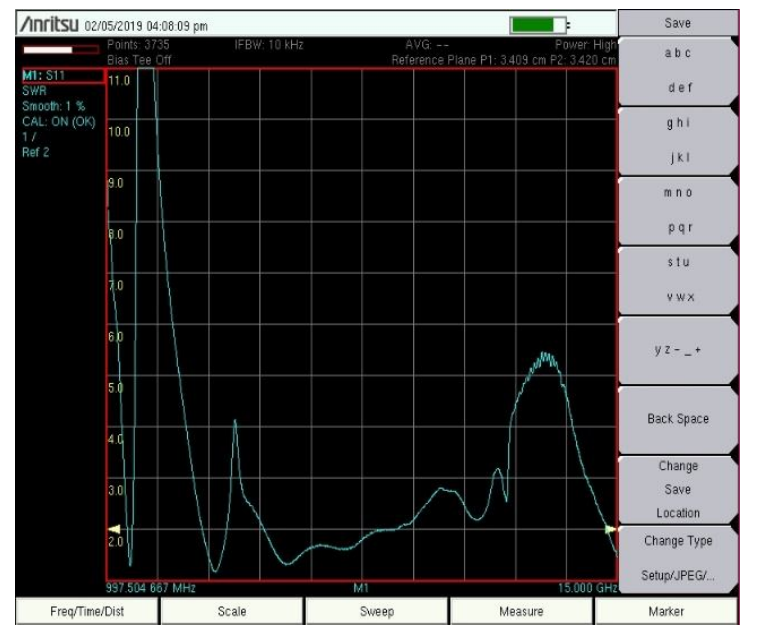

(b)

Figure 10: Measured (a) RL (b) VSWR for fabricated antenna.

The simulated 2D patterns of the proposed dual notch band antenna at frequencies of 3.5, 5, 6, 9, 10.6 GHz respectively are shown in figure 11. For a frequency of $3.5 \mathrm{GHz}$ and $5 \mathrm{GHz}$ frequency the directivity, main lobe directions are $2.094 \mathrm{dBi}$, 
$177^{\circ}$ and $2.239 \mathrm{dBi}, 179^{\circ}$ respectively. The gain at the above frequencies is $2.09 \mathrm{~dB}$ and $2.24 \mathrm{~dB}$. Similarly, at a frequency of $6 \mathrm{GHz}$ the directivity, main lobe direction and gain are $2.786 \mathrm{dBi}, 178^{\circ}$ and $2.79 \mathrm{~dB}$. At a frequency of $9 \mathrm{GHz}$ frequency, there is a sudden increase in directivity to 4.703 $\mathrm{dBi}$ and a reduction in main lobe direction to $158^{\circ}$ with a gain of $4.7 \mathrm{~dB}$. But for a frequency of $10.6 \mathrm{GHz}$ frequency, there is a slight abnormal change in directivity as it decreased to $2.411 \mathrm{dBi}$ and has main lobe direction as $138^{\circ}$ which has slight irregular radiation pattern. Even the gain has reduced to $2.4 \mathrm{~dB}$. By the observation $2 \mathrm{D}$, radiation patterns are almost identical for the frequencies ranging from $3.5 \mathrm{GHz}$ to $9 \mathrm{GHz}$. The directivity also slightly increased along with the frequency till $9 \mathrm{GHz}$. According to the simulated radiation pattern, the antenna exhibits a constant radiation pattern from $3.5 \mathrm{GHz}$ to $9 \mathrm{GHz}$ with very fewer side lobes. Hence it can be used for multiple applications in different frequency ranges.

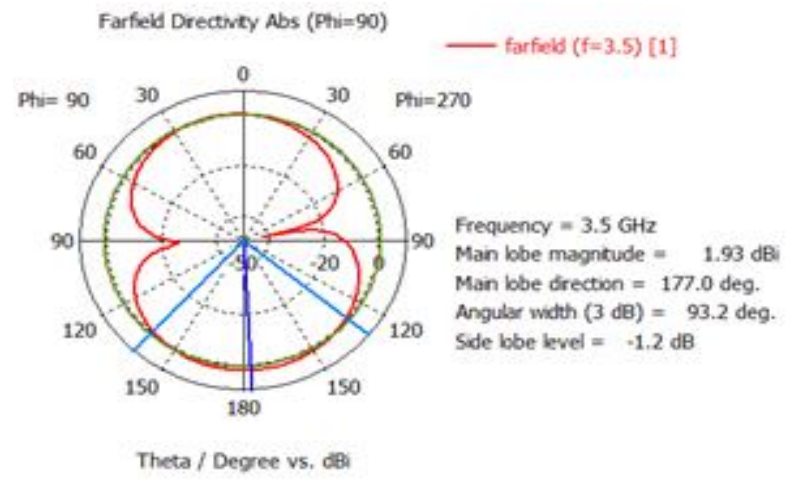

(a)

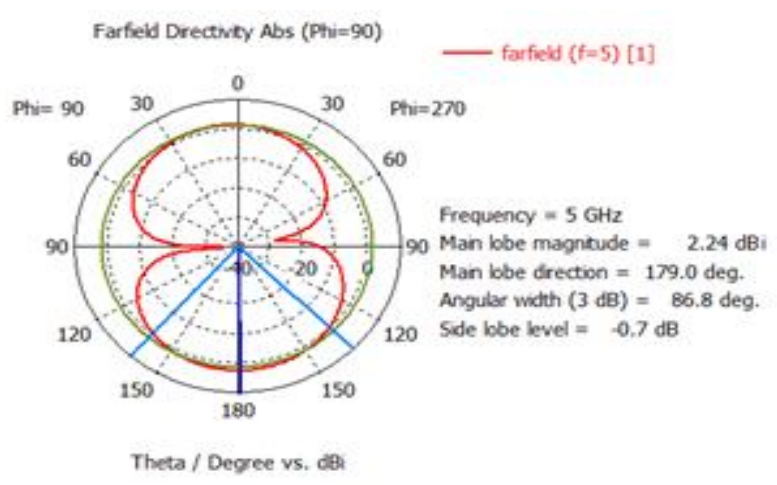

(b)

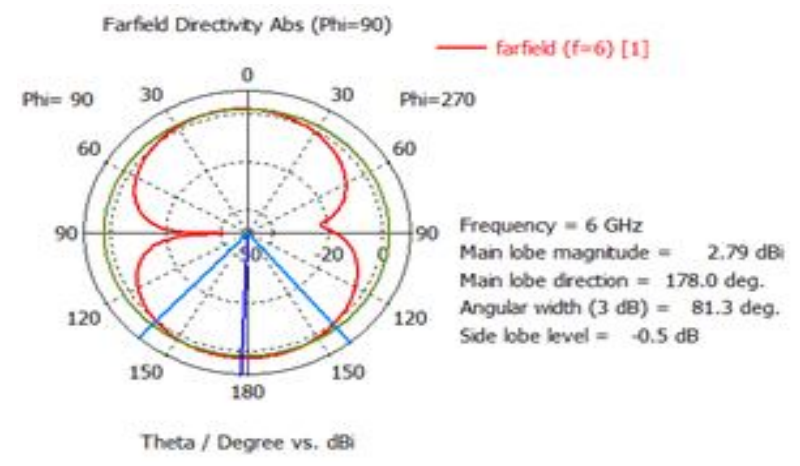

(c)

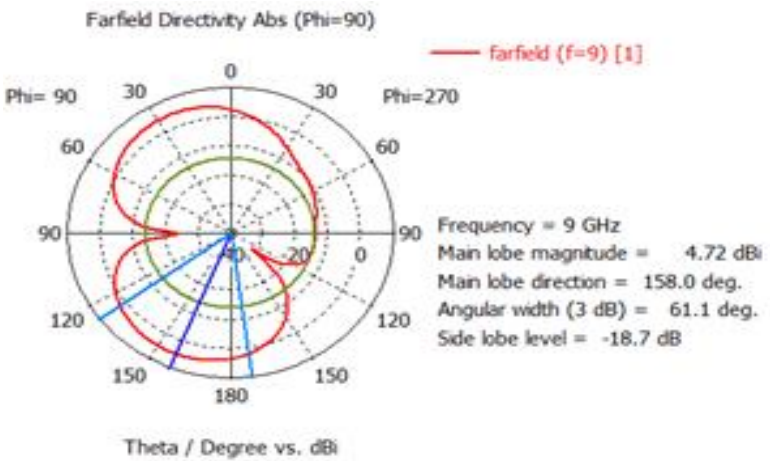

(d)

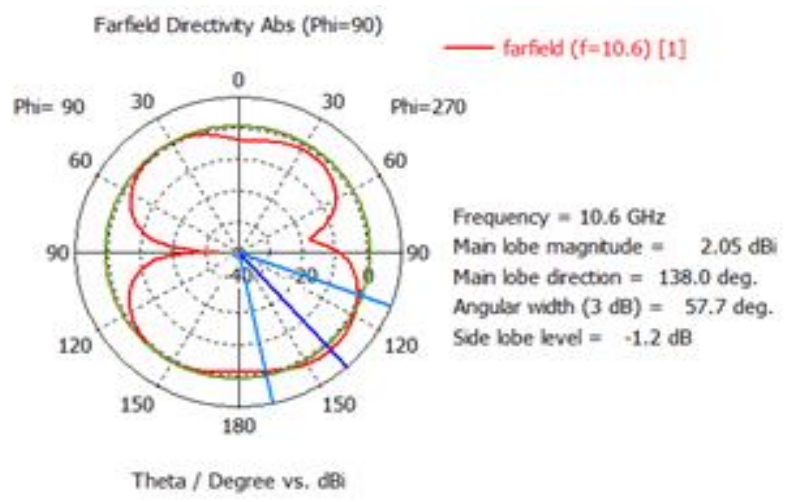

(e)

Figure 11: Radiation Pattern of proposed dual notch band UWB antenna at frequencies (a) 3.5 (b) 5 (c) 6 (d) 9 and (e) $10.6 \mathrm{GHz}$.

The proposed rectangular dual notch antenna has dimensions of $20 \times 17 \mathrm{~mm}^{2}$, the compactness of the dual notch antenna has used in several wireless applications. Moreover, the developed proposed antenna has several advantages like low fabrication cost due to single-side printing, compact size (only $340 \mathrm{~mm}^{2}$ ), Omni-directional and bidirectional radiation patterns, low cross-polarization field component, and acceptable peak gains. $3.216 \mathrm{GHz}-3.99 \mathrm{GHz}$ and $4.29 \mathrm{GHz}$ $-4.78 \mathrm{GHz}$.

\section{CONCLUSION}

A compact rectangular Dual notch UWB antenna for Wireless Personal Communications is designed, simulated and measured results are presented in this paper. The proposed antenna has a simple rectangular structure of staircase-shaped radiating patch. The SRR and CSRR slots are included in the proposed antenna to get the notch band characteristics. The SRR and CSRR slots are optimized, SRR is responsible for the notch band of frequency range from $3.216 \mathrm{GHz}$ to $3.99 \mathrm{GHz}$ and the CSRR is responsible for 4.29 $\mathrm{GHz}$ to $4.78 \mathrm{GHz}$. The simulated results of return loss and VSWR of the proposed dual notch band structure are A good agreement with the measurement results. The proposed antenna has several advantages with the literature in terms of size, Omni-directional patterns, and peak gain. 


\section{REFERENCES}

1. B Yuan, P Gao, S He, L Xu, HT Guo. A novel triple-band rectangular ring antenna with two $L$-shaped strips for WiMAX and WLAN applications. Progress In Electromagnetics Research, Vol. 40, pp. 15-24, 2013. https://doi.org/10.2528/PIERC13040703

2. VS Reddy, V Agarwal, MSG Prasad, BTP Madhav, M Bhavana, N Nikilesh, ADV Surya Prasad, B Jayaram. A novel ultra-wide band CPW fed printed antenna for IoT wireless applications. International Journal of Engineering and Advanced Technology, Vol. 8, pp. 1817-1823, 2019.

3. J Pei, AG Wang, S Gao, W Leng. Miniaturized triple-band antenna with a defected ground plane for WLAN/WiMAX applications. IEEE Antennas and Wireless Propagation Letters, Vol. 10, pp. 298-301, 2011. https://doi.org/10.1109/LAWP.2011.2140090

4. JH Yoon. Fabrication and measurement of a monopole antenna with three arc-shaped strips for WLAN/WiMAX applications. Microwave and Optical Technology Letters, Vol. 56, pp. 2061-2066, 2014. https://doi.org/10.1002/mop.28502

5. VS Reddy, MSG Prasad, BTPM Abhishek Saurav, D Apparao, GG Srujana, V Gopichand. Design and analysis of triple band fractal antenna for UWB applications. International Journal of Innovative Technology and Exploring Engineering, Vol. 8, pp. 3043-3048, 2019.

6. M Singh Ramdev. Comparative Analysis of LTE-LAA and Wi-Fi Systems in Various Domains. International Journal of Advanced Trends in Computer Science and Engineering, Vol. 8, pp. 758-763, 2019.

https://doi.org/10.30534/ijatcse/2019/66832019

7. S Kanithi, S Mahule, A Gupta. Hybrid Cylindrical Dielectric Resonator Antenna for Microwave Applications. International Journal of Advanced Trends in Computer Science and Engineering, Vol. 7, pp. 17-19, 2018. https://doi.org/10.30534/ijatcse/2018/03722018

8. JJ Xie, XS Ren, YZ Yin, SL Zuo. Rhombic slot antenna design with a pair of straight strips and two $\cap$-shaped slots for WLAN/WiMAX applications. Microwave and Optical Technology Letters, Vol. 54, pp. 1466-1469, 2012. https://doi.org/10.1002/mop.26837

9. M Samsuzzaman, T Islam, NH Abd Rahman, MRI Faruque, JS Mandeep. Compact modified swastika shape patch antenna for WLAN/WiMAX applications. International Journal of Antennas and Propagation, Vol. 2014, pp., 2014.

https://doi.org/10.1155/2014/825697

10. XL Sun, L Liu, SW Cheung, TI Yuk. Dual-band antenna with compact radiator for $2.4 / 5.2 / 5.8 \mathrm{GHz}$ WLAN applications. IEEE Transactions on Antennas and Propagation, Vol. 60, pp. 5924-5931, 2012.

https://doi.org/10.1109/TAP.2012.2211322
11.FC Ren, FS Zhang, JH Bao, B Chen, YC Jiao. Compact triple-frequency slot antenna for wlan/wimax operations. Progress in Electromagnetics Research Letters, Vol. 26, pp. 21-30, 2011. https://doi.org/10.2528/PIERL11071906

12. XL Sun, SW Cheung, TI Yuk. A compact monopole antenna for WLAN applications. Microwave and Optical Technology Letters, Vol. 56, pp. 469-475, 2014. https://doi.org/10.1002/mop.28106 